\title{
ENDOVASCULAR TREATMENT FOR INTRACRANIAL INFECTIOUS ANEURYSMS
}

\author{
Eduardo Wajnberg ${ }^{7}$, Fernanda Rueda ${ }^{2}$, Edson Marchiori', Emerson L. Gasparetto ${ }^{4}$
}

\begin{abstract}
Objetive: To re-enforce an alternative, less aggressive treatment modality in the management of intracranial infectious aneurysms. Method: We present a series of five patients with infectious endocarditis and intracranial infectious aneurysms (mycotic aneurysms) managed by means of endovascular treatment. Results: Endovascular treatment was executed technically uneventfully in all patients. Three patients had favorable clinical outcome: two were classified as Glasgow Outcome Scale 4/5, and one had total neurological recovery (GOS 5/5). Two patients died (GOS 1/5), one in consequence of the initial intracranial bleeding and the other after cardiac complications from endocarditis and open-heart surgery. Conclusion: Endovascular techniques are an expanding option for the treatment of IIAs. It has been especially useful for infectious endocarditis patients with IIA, who will be submitted to cardiac surgery with cardiopulmonary bypass and anticoagulation, with the risk of intracranial bleeding.
\end{abstract}

KEY WORDS: infectious aneurysms, cerebral, embolization

\section{Tratamento endovascular de aneurismas infecciosos intracranianos}

Resumo - Objetivo: Enfatizar o método endovascular como uma opção de tratamento alternativa e menos agressiva no tratamento de aneurismas infecciosos intracranianos. Método: Apresentamos uma série de cinco pacientes com endocardite infecciosa e aneurismas infecciosos intra-cranianos (aneurismas micóticos) tratados através da via endovascular. Resultados: $O$ tratamento endovascular teve sucesso técnico e sem intercorrências relacionadas ao cateterismo em todos os casos. Três pacientes tiveram desfecho clínico favorável: dois com escala de regeneração de Glasgow $4 / 5$ e um com recuperação neurológica completa (GOS 5/5). Dois pacientes tiveram desfecho desfavorável (GOS 1/5), um devido às conseqüências do sangramento intracraniano inicial e outro devido a complicações cardíacas da endocardite e cirurgia de troca valvar. Conclusão: As técnicas endovasculares são uma nova opção de tratamento dos aneurismas infecciosos intracranianos. Ela é especialmente útil em pacientes que serão submetidos à cirurgia cardiaca com circulação extra-corpórea e anticoagulação, com o conseqüente risco de hemorragia intracraniana.

PALAVRAS-CHAVE: aneurismas infecciosos, cerebral, embolização.

Intracranial infectious aneurysms (IIA), previously known as mycotic aneurysms, typically develop in the presence of bacterial endocarditis ${ }^{1}$. Neurological complications develop in $20 \%$ to $40 \%$ of infectious endocarditis patients ${ }^{2}$, and only $5 \%$ are caused by a ruptured aneurysm ${ }^{3}$. The infectious aneurysms result from septic embolization of left valvar vegetations to the arterial vasa vasorum.

The arterial branching points are the most common place where these emboli impact. Most of these aneurysms are distal and involve the middle cerebral artery, ${ }^{1,2}$ The overall mortality rate among these patients is $60 \%$, and increases to $80 \%$ in cases associated with subarach- noid hemorrhage $(\mathrm{SAH})^{2,4,5}$. IIAs can be treated with antibiotic therapy alone, with an unpredictable evolution: they can regress, enlarge, stabilize or even rupture ${ }^{6}$. In patients treated with surgery or, more recently, endovascular techniques (EVT), occlusion of the IIAs can be achieved ${ }^{7,8}$.

We report five cases of IIAs associated with endocarditis, which were treated with endovascular techniques.

\section{METHOD}

Diagnostic criteria

The following diagnostic criteria for endocarditis were considered: clinical symptoms, such as fever; major embolic events

Department of Radiology and Interventional Neuroradiology of the Federal University of Rio de Janeiro, Rio de Janeiro RJ, Brazil: ${ }^{1}$ Médico do Serviço de Radiodiagnóstico do Hospital Universitário Clementino Fraga Filho (HUCFF), Universidade Federal do Rio de Janeiro (UFRJ), Rio de Janeiro RJ, Brasil; ${ }^{2}$ Médico Residente do Serviço de Radiodiagnóstico do HUCFF/UFRJ; ${ }^{3}$ Professor Associado de Radiologia da Faculdade de Medicina da UFRJ e Professor Titular de Radiologia da Faculdade de Medicina da Universidade Federal Fluminense, Niterói RJ, Brasil; ${ }^{4}$ Professor Adjunto de Radiologia da Faculdade de Medicina da UFRJ. 
and a transthoracic echocardiography showing vegetations on the valves, accordingly with modified Duke's criteria ${ }^{2,9}$. In addition, a new pansystolic murmur in cardiac area and other general symptoms were also considered.

The IIAs diagnoses were achieved with angiography in all cases. The following criteria were used: presence of endocarditis; the aneurysm should be distal, involving segments 2, 3 or 4 of the middle cerebral artery or posterior cerebral artery; or proximal, involving segments $\mathrm{M} 1$ and $\mathrm{P} 1$ in association with at least two of the following criteria: (a) a change in aneurysm size or morphology on consecutive angiograms (ie, a change in the appearance of the aneurysm or a reduction or increase in its volume on a second angiogram), (b) the presence of another intraor extra-cranial mycotic aneurysm, (c) rupture of the aneurysm, (d) arterial occlusion or stenosis adjacent to the aneurysm, (e) cerebral infarction due to arterial occlusion at the level of the aneurysm and (f) recent neurological focal deficit associated with new aneurysm detection ${ }^{6}$.

Since IIA usually forms within 48 hours of embolization (time between the prodroms and the development of the aneurysm), we favored four-vessel cerebral angiography (CAG) in all patients with infective endocarditis who experienced a transient neurological focal deficit during the acute phase of the illness. The exams were performed at least 48 hours after the event. If negative, a second angiography was done after antibiotic therapy had finished, or before the need of long-term anticoagulation (patients with prosthetic heart valves). It was also recommended for patients with headache, red blood cells in the cerebrospinal fluid and in any case of non-focal neurological symptom before initiating anticoagulation ${ }^{10}$.

\section{Patient selection}

This study included five patients (four men and one woman, mean age 45 years, ranging from 33 to 59 years) who were referred to our hospital between 2002 and 2006 with the diagnosis of infectious endocarditis and underwent endovascular treatment of IIA.

All patients had valve vegetations and clinical symptoms. In most cases, blood culture was negative. In only one case blood cultures were positive, and Enterococcus was isolated. The presumed cause of the negative blood cultures was previous antibiotics administration. No history of previous cardiac disease was observed. All patients had mitral valve involvement and only one had aortic valve damage. One patient had diplopia and III cranial nerve palsy, and this was the only one who had a nonhemorrhagic presentation. The other four patients suffered severe headaches associated to loss of conscious as the initial neurological symptoms due to the aneurysm rupture.

The first mentioned patient was the only unruptured aneurysm in this series. The others cases had on initial CT scans subarachnoid hemorrhage (Fisher IV) ( $n=3)$ and parenchymal hematoma $(n=4)$ without premonitory symptoms. None of the patients had the cerebral hemorrhage as the first symptom of en- docarditis. Four of them were already in antibiotics therapy at the time of the neurological event (therapy time ranged from 7 to 14 days, mean 9 days). The time between the beginning of the endocarditis and the neurological symptoms ranged from 30 to 60 days (mean 45 days). One patient entered the hospital after the aneurysm ruptured without previous antibiotics therapy. Two patients had a long-term follow-up angiogram. None of the patients had a rehemorrhage after treatment.

\section{Angiographic characteristics}

All patients underwent four-vessel cerebral angiography with digital subtraction unit (AngioStar, Siemens. Erlagen, Germany). The IIAs locations were basilar tip, left P3, left M3, left P2 and left PICA and the size ranged from less than $1 \mathrm{~mm}$ up to $7 \mathrm{~mm}$ (mean $4 \mathrm{~mm}$ ).

All subjects had only one detected aneurysm. Most of these aneurysms were fusiforme, irregular-shaped and without neck ${ }^{11}$, making parent-vessel occlusion a frequent therapeutic choice. A favorable neck-to-dome ratio was present in only 2 cases in which a selective standard coil embolization technique was performed.

\section{Endovascular technique}

The patient informed consent was obtained in all cases. Endovascular therapy was always performed under general anesthesia. A routine coaxial technique with femoral arterial puncture was used. A 6 Fr. Guiding catheter (Envoy-Cordis, Miami, Fla or Guider Soft tip- Boston Scientific - Target Therapeutics - Fremont, CA, USA) was positioned at the cervical level with continuous flushing with normal saline. The patients underwent anticoagulation with intravenous heparin to obtain an activated clotting time two to three times baseline.

An over the wire microcatheter (SL 10 or Excel 14 - Target Therapeutics, Fremont, CA, USA) or flow-guided microcatheter (Ultra Flow 1.5 or Marathon 1.2 - MicroTherapeutics, Inc., Irvine, CA, USA) was navigated to the target zone under simultaneous subtracted fluoroscopy. The microcatheter was positioned inside the aneurysm for coiling or as close as possible in cases of parent vessel occlusion. Selective Wada test, to help to determine the eloquence of the parent vessel, was not performed. For parent vessel occlusion, cyanoacrylate was used (Histoacryl - BBraun, Melsungen, Germany), mixed with iodized oil (Lipiodil Ultra-Fluid - Guerbet, Paris, France) in rations varying from 1:2 to 1:4. Selective aneurysm occlusion was performed with Guglielmi Detachable coils (GDC - Target Therapeutics, Fremont, CA, USA) using standard technique. An immediate control angiogram was performed after each procedure, and heparin was discontinued.

\section{RESULTS}

Data from all patients are described in the Table. Endovascular treatment was executed technically uneventfully in all patients. Three patients had favorable clinical outcome: two were classified as Glasgow Outcome Scale of $4 / 5$, and one of them had total neurological recovery 
Table. Clinical, demographic and treatment data.

\begin{tabular}{|c|c|c|c|c|c|c|c|c|c|}
\hline $\begin{array}{c}\text { Ident } \\
\text { age/sex }\end{array}$ & $\begin{array}{c}\text { Time of } \\
\text { ATB (days) }\end{array}$ & $\begin{array}{l}\text { Valvar } \\
\text { injury }\end{array}$ & $\begin{array}{l}\text { Cardiac } \\
\text { surgery }\end{array}$ & $\begin{array}{l}\text { Aneurysm } \\
\text { type }\end{array}$ & $\begin{array}{l}\text { Neurological } \\
\text { symptoms }\end{array}$ & CT & Treatment & $\begin{array}{c}\text { ACG } \\
\text { control }\end{array}$ & $\begin{array}{c}\text { Outcome } \\
\text { GOS }\end{array}$ \\
\hline $\begin{array}{c}\mathrm{P} 1 \\
39 / \mathrm{M}\end{array}$ & 6 & Mitral & No & $\begin{array}{l}\text { Basilar } \\
\quad \text { tip }\end{array}$ & Diplopy & ND & $\begin{array}{l}\text { Selective } \\
\text { with coils }\end{array}$ & No & 5 \\
\hline $\begin{array}{c}\mathrm{P} 2 \\
40 / \mathrm{M}\end{array}$ & 5 & $\begin{array}{l}\text { Mitral/ } \\
\text { Aortic }\end{array}$ & Yes & $\begin{array}{l}\text { Left distal } \\
\text { PCA }\end{array}$ & $\begin{array}{l}\text { Sudden } \\
\text { headache }\end{array}$ & $\begin{array}{r}\mathrm{ICH}+\mathrm{SAH} \\
\text { (Fisher IV) }\end{array}$ & $\begin{array}{c}\text { Non selective with } \\
\text { cyanoacrylate }\end{array}$ & No & 1 \\
\hline $\begin{array}{c}\mathrm{P} 3 \\
33 / \mathrm{F}\end{array}$ & None & Mitral & No & $\begin{array}{l}\text { Left distal } \\
\text { MCA }\end{array}$ & Disorientation & $\mathrm{ICH}$ & $\begin{array}{c}\text { Selective } \\
\text { with coils (6 coils) }\end{array}$ & Yes & 5 \\
\hline $\begin{array}{c}\text { P4 } \\
59 / M\end{array}$ & 14 & Mitral & No & $\begin{array}{l}\text { Left } \\
\text { PCA }\end{array}$ & $\begin{array}{c}\text { Sudden } \\
\text { occipital pain }\end{array}$ & $\begin{array}{c}\text { SAH } \\
\text { (Fisher IV) }\end{array}$ & $\begin{array}{c}\text { Non selective with } \\
\text { cyanoacrylate }\end{array}$ & No & 1 \\
\hline $\begin{array}{c}\mathrm{P} 5 \\
54 / \mathrm{M}\end{array}$ & 30 & Mitral & Yes & PICA & $\begin{array}{c}\text { Sudden } \\
\text { headache + } \\
\text { disorientation }\end{array}$ & $\begin{array}{c}\text { SAH } \\
\text { (Fisher IV) }\end{array}$ & $\begin{array}{c}\text { Non selective with } \\
\text { cyanoacrylate }\end{array}$ & Yes & 4 \\
\hline
\end{tabular}

SAH, subarachnoid hemorrhage; ICH, intracranial hemorrhage; PCA, posterior cerebral artery; MCA, middle cerebral artery; PICA, positive inferior cerebellar artery; GOS, Glasgow Outcome Scale.
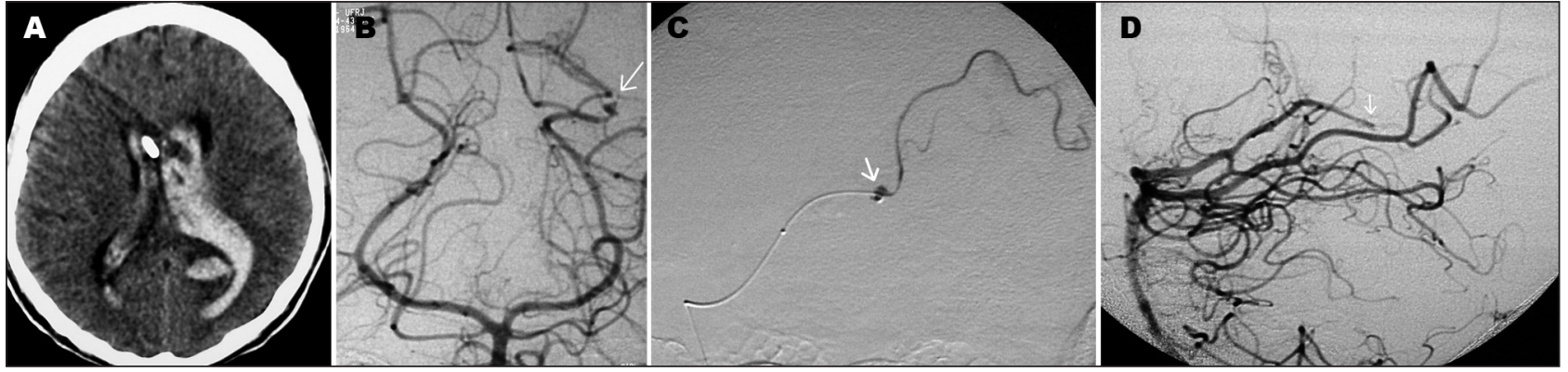

Fig 1. Patient 2. (A) CT scan shows hemoventricle after sudden headache. (B) Left vertebral angiogram revealed a tiny aneurysm at the P3 segment of the left PCA (arrow). (C) Selective angiogram depicts distal catheter's position and the aneurysm (arrow) within the parent vessel, both were embolized by cyanoacrylate. (D) Final lateral angiogram showing aneurysm and parent vessel (proximal Left P3 segment) occlusion (arrow).
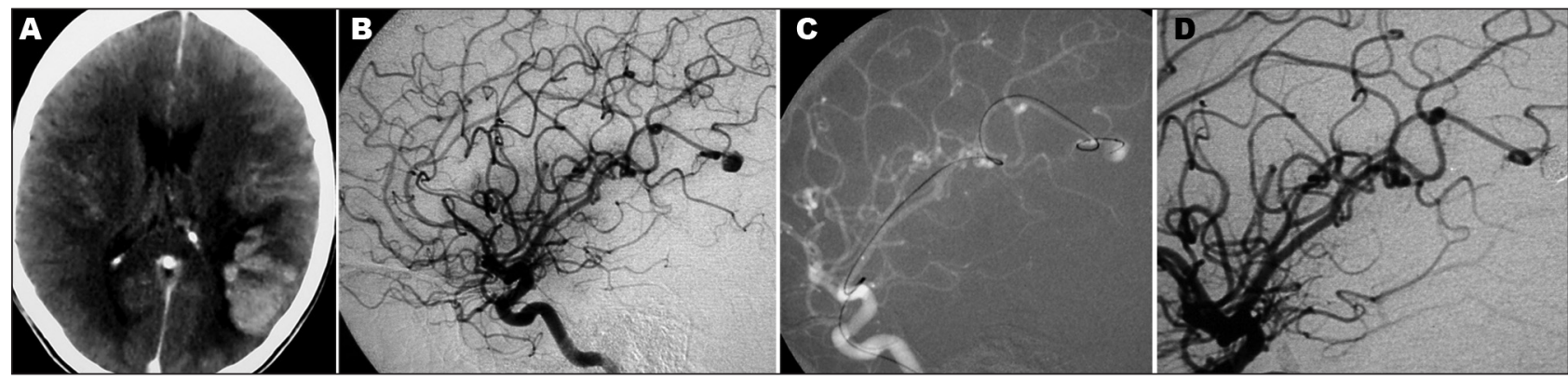

Fig 2. Patient 3. (A) CT scan after neurological event revealed left parietal intracranial hemorrhage in correspondence with left M3 infectious aneurysm. (B) Left Internal carotid angiography shows a distal angular artery saccular aneurysm. (C) Selective microcatheterisation using overthe-wire technique with SL10 microcatheter. (D) Control angiogram after embolization with coils. Parent vessel was not obstructed.

(GOS 5/5). Two patients died (GOS 1/5), one in consequences of the initial intracranial bleeding and the other after cardiac complications from endocarditis and openheart surgery.

Patient 1 had a basilar tip aneurysm, which was treated with selective coils embolization, with preservation of the parent vessel. This patient had slowly resolution of the third nerve palsy. The other patients had distal aneurysms and were treated with cyanoacrylate in three cases and in one subject we used selective embolization with coils.

Patient 2 (Fig 1) had a Fisher grade IV subarachnoid hemorrhage caused by a very small aneurysm (less then $1 \mathrm{~mm}$ in diameter) of the parieto-occiptal branch of the posterior cerebral artery. Treatment with tiny drop of cy- 

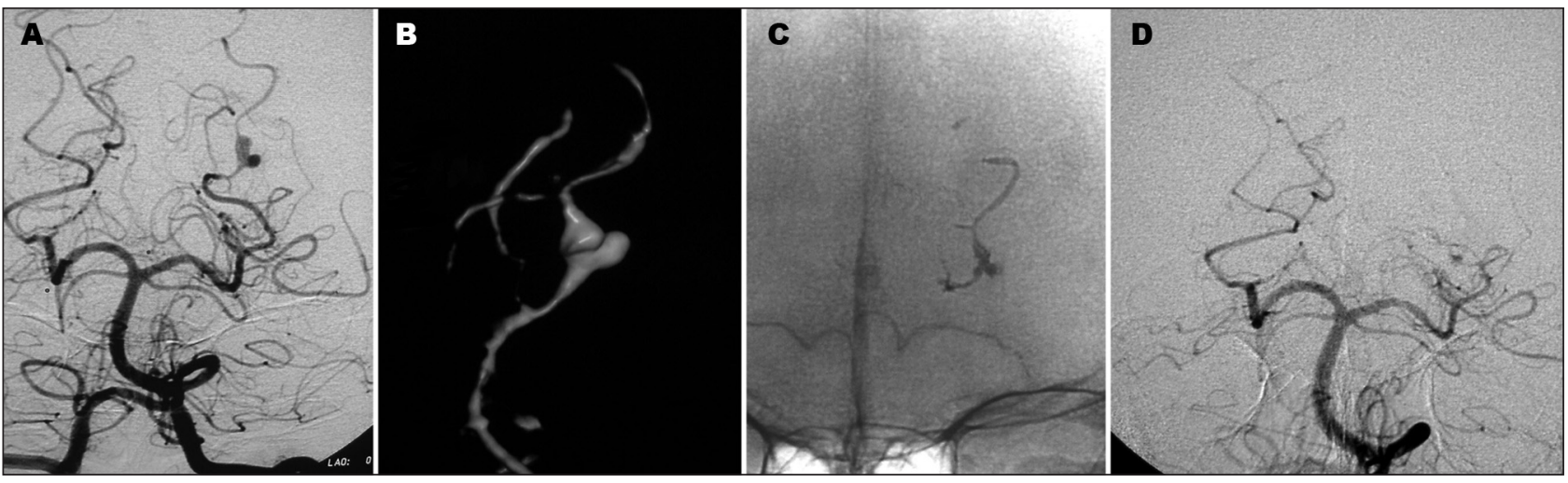

Fig 3. Patient 4. Left P2 aneurysm. (A, B) Angiogram and 3D rotational angiography shows well depicted bilobulated aneurysm dome before treatment. (C, D) Histoacryl cast inside the IAA and the parent vessel, with parent vessel occlusion.

anoacrylate in the parent vessel was done. However, after an open heart surgery he died due to sepsis and acute respiratory distress syndrome.

The patient 3 recovered well after embolization of a very distal angular artery aneurysm (6 $\mathrm{mm}$ ) (Fig 2), without neurological disability. Three days after the procedure, she initiated seizures. The CT scan revealed a left frontal intracranial hemorrhage, away from the site of the embolization. Another cerebral angiography performed four days after the event showed no new IIA. She recovered well from the bleeding, with good neurological recovery. The follow-up angiography, one year latter, showed neither aneurysm recanalization, nor a new aneurysm formation.

Patient 4 had a distal aneurysm (Fig 3) treated with nonselective embolization with cyanoacrylate successfully, but he died as a consequence of the initial hemorrhage.

Patient 5 also had a distal aneurysm, located in the vermian branch of the left PICA, which bled causing a Fisher grade IV subarachnoid hemorrhage. After selective micro catheterization of the vermian branch of the PICA, cyanoacrylate was used to occlude both the aneurysm and the parent vessel. This patient had a near-complete neurological recovery, persisting with mild degree of cerebellar syndrome. A 1-year follow-up angio-CT showed persistent occlusion of the aneurysm and the parent vessel.

\section{DISCUSSION}

Infectious endocarditis diagnosis is usually based on Duke's criteria: Major criteria are isolation of typical organism in 2 separate cultures or persistently positive blood cultures and positive echocardiogram (vegetation, abscess) or new valvular regurgitation. Minor criteria are predisposition, fever $>38.0^{\circ} \mathrm{C}\left(100.4{ }^{\circ} \mathrm{F}\right)$, vascular or immunological phenomena (splinter hemorrhages, Osler's nodes), positive blood cultures and positive findings on echocardiogram (not meet major criteria). Clinical criteria for infective endocarditis require two major criteria, or one major and three minor criteria, or five minor criteria.

Our diagnostic criteria for IIA were based on the association of infectious endocarditis with classically described IIA, being this a distal aneurysm, with irregular walls, without neck ${ }^{11}$. As there is involvement of the muscular layer after adventitia inflammation related to the septic emboli, the IIA is, actually, a pseudo-aneurysm. Although some authors report up to $25 \%$ of patients with multiple aneurysms ${ }^{11,12}$, in our series each patient had only one IIA. Regarding the basilar tip aneurysm, the doubt of being infectious or a berry aneurysm discovered incidentally could be raised. We considered previously cited diagnostic criteria in the literature such as arterial stenosis close to the aneurysm ${ }^{13}$, rapid morphologic changes ${ }^{14}$, and we also considered development of new neurological symptom as a signal (in this case, third nerve palsy). There are also other reports treating basilar tip aneurysm associated with infectious endocarditis ${ }^{12}$.

In this series, all patients were already in use of antibiotics when endovascular treatment was done. Theoretically, the introduction of foreign material into an infected area could result in prolonged infection and abscess formation ${ }^{6}$. We didn't observe that complication in our five cases, as well as in other reports ${ }^{6,12}$. Besides, septic emboli during effective antimicrobial therapy and/or associated with non-virulent organisms can injure the arterial wall leading to subacute development of aneurysm that are often aseptic at the time of rupture ${ }^{15}$, thus aseptic at the time of the EVT.

Another cause of brain complication in untreated endocarditis is intracranial hemorrhage caused by septic emboli that achieve the cerebral arteries, during uncontrolled bacteremia, causing erosive arteritis ${ }^{1,15}$. There is also a possibility of sterile emboli cause ischemic infarct that undergo secondary hemorrhagic transformation ${ }^{15}$. IIA also can be obliterated by the hemorrhages that they 
produce, being hard to be identified ${ }^{12,15}$. These could be explanations to the second bleeding of patient number 3 , which was away from the site of first embolization, and no IIA was found on a subsequent angiographic study.

Management of IIA is controversial and many algorithms were created to help guidance of the treatment. Some authors suggested treating unruptured aneurysm with only antibiotics therapy and serial cerebral angiograms $^{1,11}$. If the aneurysm has ruptured and no cerebral hematoma was formed or if it is located in a non-eloquent area, EVT could be used. In the opposite way, surgery should be considered ${ }^{1,11}$. In our series, EVT was always preferred, in any clinical condition or underlying disease. The use of cyanoacryalate allowed the occlusion of both, the aneurysm and the parent vessel. This was the choice when the aneurysm was fusiforme, involving more then $50 \%$ of the circumference of the artery. In this series, $60 \%$ of the patients had this treatment modality. In such a procedure, there is a theoretical risk of rupture associated with a rapid burst of increased pressure in the artery stump ${ }^{6,16}$, but we haven't noticed that. In the other two cases (40\%), coils were the EVT option. The microcatheter was well positioned at the aneurysm's neck and 2 to 6 coils were used to occlude the aneurysm sac. The theoretical disadvantages of the coils include the risk of perforating the aneurysmatic sac, as the walls are inflamed and fragile, and the need of a larger inner diameter microcatheter to the procedure ${ }^{6}$. A favorite aspect of using coils is the possibility of allowing parent vessel preservation, reducing the chances of cerebral infarct as consequence of embolization $^{6}$. We haven't had a perforation of the IIA during the embolization, neither because of coils, nor because of the increased pressure when using cyanoacrylate.

The mortality rate among patients with endocarditis and ruptured IIA varies among $60 \%$ to $80 \%{ }^{2}$. In our series the mortality rate was $40 \%$. One patient died during cardiac surgery and one after embolization. The others had good neurological recovery (GOS scores 4 or 5). In our algorithm, patients who do not have a hematoma producing mass effect or increased ICP and whose aneurysm does not involve an eloquent vascular territory are treated by a percutaneous approach. Therefore, endovascular therapy is the first option for patients with ruptured aneurysms who are in stable condition. Several important advantages of endovascular therapy justify this approach. First, improvements in catheter technology have made distal aneurysms more accessible. Second, endovascular occlusion can be accomplished with minimal aneurismal manipulation and risk of re-rupture. So, corroborating the literature, our series showed a good result of the EVT, although it is too small to conclude the efficacy of the method. EVT also allows cardiac surgery to be earlier, as consequence of a faster recovery, than it would be if craniotomy is performed'.

In conclusion, endovascular techniques are an expanding option for the treatment of IIAs. It has been especially useful for infectious endocarditis patients with IIA, who will be submitted to cardiac surgery with cardiopulmonary bypass and anticoagulation, with the risk of intracranial bleeding ${ }^{17}$. Although the introduction of foreign material into an infected area could result, theoretically, in prolonged infection, we didn't observe any infectious complication in our series. Larger series, with long-term angiographic follow-up of this technique may be necessary to ensure the safety, effectiveness and durability of the endovascular treatment of IIA.

\section{REFERENCES}

1. Peters PJ, Harrison T, Lennox JL. A dangerous dilemma: management of infectious intracranial aneurysms complicating endocarditis. Lancet Infect Dis 2006;6:742-748.

2. Baddour LM, Wilson WR, Bayer AS, Fowler VG, Bolger AF, Levison ME. Infective endocarditis: diagnosis, antimicrobial therapy, and management of complications: a statement for health care professionals from the Committee of Rheumatic Fewer, Endocarditis and Kawasaki Disease, Council of Cardiovascular disease in the young, and the Councils on Clinical Cardiology, Stroke, and Cardiovascular Surgery and Anesthesia, American Heart Association: Endorsed by the Infectious Diseases Society of America. Circulation 2005;111:394-434.

3. Frizzell RT, Vitek JJ, Douglas CMD, Fisher WS. Treatment of bacterial (mycotic) intracranial aneurysm using an endovascular approach. Neurosurgery 1993;32:852-854.

4. Watanabe A, Hirano K, Ishii R. Cerebral mycotic aneurysm treated with endovascular occlusion: case report. Neurol Med Chir (Tokyo) 1998;38:657-660.

5. Clare CE, Barrow DL. Infectious intracranial aneurysm. Neurosurg Clin N Am 1992;3:551-566.

6. Chapot R, Houdart E, Saint-Maurice JP, Aymard A, Mounayer C, Lot G. Endovascular treatment of cerebral mycotic aneurysms. Radiology 2002;222:389-396

7. Frazee JG, Cahan LD, Winter J. Bacterial intracranial aneurysms. J Neurosurg 1980;53:633-641.

8. Brust JC, Dickinson PC, Hughes JE, Holtzman RN. The diagnosis and treatment of cerebral mycotic aneurysms. Ann Neurol 1990;27:238-246.

9. Li JS, Senton DJ, Mick N, Nettles R, Fouler VGJr, Ryan T. Proposed modifications to the Duke criteria for the diagnosis of infective endocarditis. Clin Infect Dis 2000;30:633-638.

10. Salgado AV, Furlan AJ, Keys TF. Mycotic aneurysm, subarachnoid hemorrhage, and indications for cerebral angiography in infective endocarditis. Stroke 1987;18:1057-1060.

11. Chun JY, Smith W, Halbach VV, Higashida RT, Wilson CB, Lawton MT. Current multimodality management of infectious intracranial aneurysms. Neurosurgery 2001;48:1203-1214.

12. Phuong LK, Link M, Wijdicks E. Management of intracranial infectious aneurysms: a series of 16 cases. Neurosurgery 2002;51:1145-1152.

13. Aoajouanine P, Castaigne P, l'Hermitte F, Cambier J. L'artérite cérébrale de la maladie d'Osler: ses complications tardives. Semaine Hop (Paris) 1959;35:1160-1165.

14. McNeel D, Evans RA, Ory EM. Angiography of cerebral mycotic aneurysms. Acta Radiol Diagn Stockh 1969;9:407-412.

15. Hart RG, Kagan-Hallet K, Joerns SE. Mechanisms of intracranial hemorrhage in infective endocarditis. Stroke 1987;18:1048-1056.

16. Cloft HJ, Kallmes DF, Jensen ME, Lanzino G, Dion JE. Endovascular treatment of ruptured, peripheral cerebral aneurysms: parent artery occlusion with short Guglielmi detachable coils. Am J Neuro 1999;20:308-310.

17. Erdogan HB, Erentug V, Bozbuga N, Goksedef D, Akinci E, Yakut C. Endovascular treatment of intracerebral mycotic aneurysm. Tex Heart Inst J 2004;31:165-167. 